\title{
Transparência e acesso à informação: um estudo da demanda por informações contábeis nas universidades federais brasileiras
}

\author{
Transparency and access to information: A study \\ of demand for accounting information \\ in Brazilian federal universities
}

\author{
Janyluce Rezende GAMA' \\ Georgete Medleg RODRIGUES²
}

\section{Resumo}

Com a edição da Lei no 12.527/11, a Lei de Acesso à Informação, o Brasil vivencia o início da implementação de uma política de acesso às informações públicas, instrumento de uma ampla política nacional com foco na transparência e no controle social dos atos públicos. O processo de convergência das normas contábeis aos padrões internacionais tem o mesmo objetivo, ou seja, de transparência na prestação de contas das informações governamentais, contábeis e financeiras. As universidades federais brasileiras, como entidades públicas, estão obrigadas a cumprir as regras de transparência e prestação de contas. Este trabalho apresenta resultados parciais de uma pesquisa de doutorado que, dentre outros objetivos, busca verificar o comportamento da demanda por informações contábeis nas universidades públicas federais após a edição da Lei de Acesso à Informação, compreendendo uma amostra de 59 universidades, nos dois primeiros anos de implementação da lei. Como metodologia, utiliza uma abordagem qualitativa, através de pesquisa bibliográfica e documental com levantamento de informações nos Relatórios Estatísticos disponíveis no portal do Sistema Eletrônico do Serviço de Informações ao Cidadão das universidades federais. Conclui que, nos dois primeiros anos da Lei de Acesso à Informação, em média, 60\% das universidades federais apresentaram demanda por informações contábeis, apesar do esforço do Governo Federal em evidenciar os dados públicos nos portais, e que o número total desse tipo de demanda manteve-se praticamente inalterado entre o primeiro e o segundo ano de implementação da Lei em questão.

Palavras-chave: Acesso à informação. Informação contábil. Informação pública. Transparência. Universidades públicas federais.

\begin{abstract}
Through Law No 12.527/11, Law on Access to Information, Brazil experiences the beginning of the implementation of a policy on access to public information, which is an instrument of extensive national policy, focusing on transparency and social control of public acts. The International Convergence of Accounting Standards has the same goal, i.e., transparency of the inventory of current state government accounting and reporting practices. The Brazilian federal universities, as public entities, are required to comply with the rules of transparency and inventory accounting. The present study shows the results of a doctoral research that, among other objectives, endeavors to verify the behavior of demand for accounting information in public federal universities, after the implementation of law on access to information. The study included a sample of 59 universities during the first two years of implementation of the law on Access to Information. In this qualitative study, we conducted a bibliographical and documentary research to collect information on the Statistical Reports of the

\footnotetext{
1 Universidade Federal do Espírito Santo, Centro de Ciências Jurídicas e Econômicas, Departamento de Ciências Contábeis. Av. Fernando Ferrari, 514 , Campus Universitário, Goiabeiras, 29075-910, Vitória, ES, Brasil. Correspondência para/Correspondence to: J.R. GAMA.E-mail: <janylucegama@gmail.com>.

2 Universidade de Brasília, Faculdade de Ciência da Informação, Programa de Pos-Graduação em Ciência da Informação. Brasília, DF, Brasil.

Recebido em 15/8/2014, reapresentado em 24/4/2015 e aceito para publicação em 20/5/2015.
} 
federal universities available on the website Electronic Citizen Service Information Systems. It may be concluded that during the first two years of the law on Access to Information, on average only $61 \%$ of the federal universities demanded financial information, despite the efforts of the federal government in disclosing public information on their websites. Furthermore, the total number of demands for information on accounting remained unchanged between the first and second year of implementation of law on Access to Information.

Keywords: Access to information. Accounting information. Public information. Transparency. Federal public universities.

\section{Introdução}

A transparência e o acesso às informações públicas são alguns dos pilares fundamentais de um governo aberto à participação social. Esse tema tem sido objeto de estudos de organismos internacionais, como o Fundo Monetário Internacional (FMI), o Banco Mundial, a Organização para a Cooperação e Desenvolvimento Econômico (OCDE) e a International Federation of Accountants (IFAC), bem como de organizações internacionais, especialistas em pesquisas de direito à informação, como a Freedom of Information Advocates Network (FOIAnet), a Access Info Europe (AIE) e a Centre for Law and Democracy (CLD).

O Governo Federal brasileiro, na tentativa de tornar as contas públicas mais transparentes, tem adotado alguns instrumentos de Políticas Públicas de Informação, mecanismos legais para auxiliar na busca por dados mais transparentes. Recursos como portais de transparência, divulgação de planos, orçamentos, prestações de contas e o respectivo parecer prévio, participação popular e realização de audiências públicas, adoção de sistema integrado de administração financeira e controle, entre outros, foram adotados por meio da Lei Complementar no 101/2000 (Brasil, 2000), também conhecida como Lei de Responsabilidade Fiscal (LRF), além da Lei Complementar no 131/09 (Brasil, 2009), do Decreto no 7.185/10 (Brasil, 2010a) e da Lei n 12.527/11, a Lei de Acesso à Informação (LAI) (Brasil, 2011b).

A Lei de Acesso à Informação também define um número mínimo obrigatório de informações a serem divulgadas, dentre as quais as contábeis, financeiras e orçamentárias como objeto de transparência ativa. Os arts. $7^{\circ}$ e $8^{\circ}$ da referida lei preveem, dentre outros, dados pertinentes a repasses ou transferências de recursos financeiros, despesas públicas, administração do patrimônio público, utilização de recursos públicos, licitação, contratos administrativos, além de informação relativa ao resultado de inspeções, auditorias, prestações e tomadas de contas realizadas pelos órgãos de controle interno e externo do governo. Na prática, os portais de transparência têm disponibilizado, primeiramente, as informações contábeis, pois seu sistema tem a finalidade de coletar os dados, classificá-los e mensurá-los monetariamente de forma a sumarizá-los em relatórios contábeis, a base para as auditorias nas instituições públicas para a prestação de contas.

A transparência das contas públicas no Brasil ganhou ainda mais evidência com a reforma da contabilidade governamental, que busca informações cada vez mais comparáveis e compreensíveis (Wynne, 2004; Chan, 2010; Van Der Hoek, 2010). Esse processo, o qual teve início com a International Federation ofAccountants (IFAC) em 1977, objetivando fortalecer mundialmente a contabilidade do setor público, desenvolveu normas contábeis de alta qualidade que já geraram impactos em diversos países (Chan, 2003; Wynne, 2004; Chan, 2010; Herbest, 2010). No Brasil, o processo de convergência no setor público teve apoio da Secretaria do Tesouro Nacional e do Conselho Federal de Contabilidade que, em 2008, atualizou as normas da contabilidade governamental com base nos padrões internacionais.

Segundo Vicente et al. (2012), os estudos sobre o processo de reforma da contabilidade aplicada ao setor público brasileiro são relevantes por abordarem um sistema de informação que deve ser capaz de instruir os cidadãos sobre as escolhas realizadas pelos seus representantes. Assim, todas as instituições do governo, em todas as esferas, veem-se obrigadas a implementar os instrumentos de transparência e acesso às informações públicas, seja por meio de portais de transparência, seja por investimentos em novos sistemas de informação.

Em relação às universidades públicas, Gant e Turner-Lee (2011) destacam o seu papel primordial no processo dos portais de transparência do governo. Para eles, essas instituições tanto podem incentivar os cidadãos a se engajarem mais na criação de conteúdos e aplicativos para esses portais, como desempenhar seu papel de líderes para projetar novos processos e fer- 
ramentas para essas plataformas. Não obstante, muitas vezes, os próprios portais de transparência das universidades são falhos em vários pontos, tanto na divulgação de informações obrigatórias pelas leis brasileiras (Platt Neto et al., 2006; Lyrio et al., 2008; Bezerra et al., 2012; Rodrigues, 2013), quanto na questão do acesso a essas informações (Pereira et al., 2013).

No contexto governamental, as universidades públicas surgem, comumente, constituídas na forma de autarquias ou fundações.Também são obrigadas pela Constituição Federal a prestar contas do uso de seus recursos e dar transparência aos atos públicos evidenciando a necessidade de transparência das contas das universidades públicas (Platt Neto et al., 2006). Porém, o que ocorre é uma relativa falta de publicidade na divulgação da prestação de contas dessas instituições na Internet (Bezerra et al., 2012). Os dispositivos de transparência ativa previstos no decreto de regulamentação da LAI, por exemplo, não estão integralmente presentes nos portais e, quando estão, nem sempre remetem ao conteúdo respectivo (Rodrigues, 2013).

Apesar de ainda ser uma área carente de estudos, uma nova visão da gestão administrativa das universidades tem recebido destaque na área acadêmica (Sleutjes \& Oliveira, 1998; Façanha, 1999; Saraiva \& Capelão, 2000; Vieira, E.F. \& Vieira, M.M.F., 2003) e são crescentes os estudos sobre o tema. Recentemente, com o aumento de pesquisas voltadas para o tema "transparência e acesso às informações públicas", as universidades federais e estaduais oferecem um campo de pesquisa importante, como demonstram os estudos de Lyrio et al. (2008); Bezerra et al. (2012); Rodrigues (2013); Costa et al. (2013); Pereira et al. (2013).

Na trilha aberta pelos trabalhos citados acima, a presente pesquisa selecionou, como universo, as universidades públicas federais que, assim como qualquer instituição governamental que compõe a estrutura da Administração Pública brasileira, são obrigadas a atender aos instrumentos de transparência das contas públicas. Buscou-se, assim, responder à seguinte questão: considerando que os instrumentos de transparência no Brasil são uma exigência cada vez mais presente na administração pública, qual seria, nesse contexto, o comportamento da demanda por informações contábeis nas universidades federais, após todo o esforço do Governo
Federal na busca pela evidenciação e transparência das informações públicas, com a construção de um arcabouço legal nos últimos anos?

Para tanto, foi utilizada como metodologia uma abordagem qualitativa, que envolve, na primeira etapa, a pesquisa bibliográfica e, na segunda, o levantamento de informações por meio dos relatórios estatísticos e download de dados disponíveis no portal do Sistema Eletrônico do Serviço de Informações ao Cidadão (e-SIC) do Governo Federal <http://www.acessoainformacao. gov.br/sistema $>$. A partir da análise de uma amostra composta por cinquenta e nove universidades públicas federais, este artigo tem como objetivo caracterizar a demanda por informações contábeis dirigidas a essas instituições quanto ao número, proporção dos pedidos e perfil dos demandantes nos dois primeiros anos de implementação da LAI.

\section{Transparência e acesso às informações públicas nas entidades governamentais brasileiras}

Entre os diversos instrumentos importantes de transparência e de prestação de contas concebidos, três podem ser considerados marcos na história da Administração Pública brasileira: a Lei n 9.755, de 16 de dezembro de 1998 (Brasil, 1998), que criou na Internet o Portal Contas Públicas; a Lei Complementar n 101, Lei de Responsabilidade Fiscal (LRF), de 4 de maio de 2000, que estabeleceu normas para a gestão fiscal responsável; e o Decreto $n^{\circ}$ 5.482, de 30 de junho de 2005 (Brasil, 2005), que criou na Internet o Portal da Transparência (Ferreira et al., 2014). Porém, ao longo dos últimos anos, outros instrumentos, como novas leis, decretos e portarias, ganharam evidência na tentativa de regulamentar o tema transparência e acesso às informações públicas. 0 Quadro 1 sintetiza alguns desses instrumentos.

Entre os instrumentos de transparência apresentados no Quadro 1 destaca-se a LAI, Lei n 12.527/11, marco da implementação de uma política de acesso às informações públicas com foco na transparência e no controle social, consagrando e disciplinando o que já estava previsto na Constituição Federal de 1988. Contudo, convém ressaltar que, para alguns autores, como Jardim (2013), o arcabouço legal não é suficiente para se afirmar 
Quadro 1. Instrumentos de políticas públicas de informação no Brasil.

\begin{tabular}{|c|c|}
\hline $\begin{array}{l}\text { Instrumentos de Políticas Públicas de } \\
\text { Informação }\end{array}$ & Objetivo \\
\hline Lei n 9.755/1998 - Homepage das "contas públicas" & $\begin{array}{l}\text { Dispõe sobre a criação de 'homepage' na 'Internet', pelo Tribunal de } \\
\text { Contas da União, para divulgação dos dados e informações que especifica, } \\
\text { e dá outras providências (Brasil, 1998). }\end{array}$ \\
\hline Lei nº 101/2000 - Lei da Responsabilidade Fiscal & $\begin{array}{l}\text { Estabelece normas de finanças públicas voltadas para a responsabilidade } \\
\text { na gestão fiscal e dá outras providências (Brasil, 2000). }\end{array}$ \\
\hline Decreto n 5.482/2005 - Portal Transparência Pública & $\begin{array}{l}\text { Dispõe sobre a divulgação de dados e informações pelos órgãos e } \\
\text { entidades da administração pública federal, por meio da Rede Mundial } \\
\text { de Computadores - Internet (Brasil, 2005). }\end{array}$ \\
\hline Portaria Interministerial n 140/2006 & $\begin{array}{l}\text { Disciplina a divulgação de dados e informações pelos órgãos e entidades } \\
\text { da Administração Pública Federal, por meio da rede mundial de compu- } \\
\text { tadores - internet - e dá outras providências (Brasil, 2006). }\end{array}$ \\
\hline LC n 131/2009 - Lei da Transparência & $\begin{array}{l}\text { Determina a disponibilização, em tempo real, de informações porme- } \\
\text { norizadas sobre a execução orçamentária e financeira da União, dos } \\
\text { Estados, do Distrito Federal e dos Municípios (Brasil, 2009). }\end{array}$ \\
\hline Decreto n 7.185/2010 - Padrão Mínimo de Qualidade do SI & $\begin{array}{l}\text { Dispõe sobre o padrão mínimo de qualidade do sistema integrado de } \\
\text { administração financeira e controle, no âmbito de cada ente da Federação } \\
\text { (Brasil, 2010a). }\end{array}$ \\
\hline Portaria MF n 548, de 22 de novembro de 2010 & $\begin{array}{l}\text { Estabelece os requisitos mínimos de segurança e contábeis do sistema } \\
\text { integrado de administração financeira e controle utilizado no âmbito de } \\
\text { cada ente da Federação. São requisitos adicionais aos previstos no } \\
\text { Decreto no 7.185, de } 27 \text { de maio de } 2010 \text { (Brasil, 2010b). }\end{array}$ \\
\hline Lei n 12.527/2011 - Lei de Acesso à Informação Pública & $\begin{array}{l}\text { Regula o acesso a informações. Dispõe sobre os procedimentos a serem } \\
\text { observados pela União, Estados, Distrito Federal e Municípios, com o fim } \\
\text { de garantir o acesso a informações (Brasil, 2011 b). }\end{array}$ \\
\hline Decreto de 15-09-2011 & $\begin{array}{l}\text { Institui o Plano de Ação Nacional sobre Governo Aberto e dá outras } \\
\text { providências (Brasil, 2011a). }\end{array}$ \\
\hline $\begin{array}{l}\text { Decreto } n^{0} 7.724 / 2012 \text { - Acesso a Informações no Poder } \\
\text { Executivo Federal }\end{array}$ & $\begin{array}{l}\text { Regulamenta no âmbito do Poder Executivo Federal os procedimentos } \\
\text { para a garantia do acesso à informação e para a classificação de infor- } \\
\text { mações sob restrição de acesso, observados grau e prazo de sigilo con- } \\
\text { forme Lei } n^{\circ} 12.527 / 2011 \text { (Brasil, 2012). }\end{array}$ \\
\hline Portaria CGU n 277, de 7 de fevereiro de 2013 & $\begin{array}{l}\text { Institui o Programa Brasil Transparente que tem por objetivo geral apoiar } \\
\text { Estados e Municípios na implementação da Lei de Acesso à Informação, } \\
\text { Lei no 12.527, de } 18 \text { de novembro de 2011, no incremento da transparência } \\
\text { pública e na adoção de medidas de governo aberto (Brasil, 2013a). }\end{array}$ \\
\hline Decreto de 12-03-2013 & $\begin{array}{l}\text { Altera o Decreto de } 15 \text { de setembro de 2011, que institui o Plano de Ação } \\
\text { Nacional sobre Governo Aberto (Brasil, 2013b). }\end{array}$ \\
\hline
\end{tabular}

Fonte: Elaborado pelas autoras (2013).

que há uma política de informações do Estado, apesar do avanço desse aspecto com a LAI. Para ele, as crescentes demandas sociais por informações públicas exigem, também, uma política de gestão de arquivos. 0 Estado brasileiro, observa Jardim (2013, p.384), possui um deficit histórico em termos de transparência informacional demonstrado, por exemplo, pela "condição periférica dos serviços e instituições arquivísticas do Estado" e pela ausência de políticas públicas arquivísticas.
Apesar das pertinentes ressalvas de Jardim (2013) citadas acima, não se pode ignorar que a criação de instrumentos de transparência no Brasil resulta de um movimento de modernização da Administração Pública, mesmo que de natureza tributária ou de diretrizes de organismos internacionais, como já apontado, ou ainda em decorrência do combate à corrupção. Esse processo busca de forma permanente a estruturação de um modelo de gestão que possa alcançar objetivos, como 
melhorar a qualidade da oferta de serviços à população, aperfeiçoar o sistema de controle social da Administração Pública e combater a corrupção (Matias-Pereira, 2012).

A transparência nas prestações de contas, ou a accountability, sinaliza que a Administração Pública está preocupada em assegurar a integridade de seus serviços, colocando-se à frente de situações que contrariam a ética no serviço público (Kanaane et al., 2010). A transparência tem-se constituído, de fato, em um instrumento de combate à corrupção, "[...] fenômeno que enfraquece a democracia, a confiança do Estado, a legitimidade dos governos e a moral pública" (Matias-Pereira, 2012, p.104).

No contexto das universidades federais, as quais são parte do setor público, é preciso considerar o relevante papel social dessas instituições. Considerando a sua missão de geração e disseminação do conhecimento e sua vocação como potencial gerador de transformações sociais, tornam-se relevantes as pesquisas nessa temática (Oliveira et al., 2013). Mais do que garantir o atendimento das normas legais, as iniciativas de transparência nas universidades públicas constituem igualmente uma política de gestão responsável que favorece o exercício da cidadania pela população. Potencialmente, a atitude poderá servir de estímulo aos estudantes, professores e demais servidores, contribuindo para o hábito de solicitar esclarecimentos às entidades governamentais (Platt Neto et al., 2006).

\section{Procedimentos metodológicos}

O presente estudo foi elaborado em duas etapas. Na primeira, foi realizada uma pesquisa bibliográfica relacionada ao tema, além do levantamento e sistematização de leis, decretos e portarias governamentais, com o intuito de entender os instrumentos de transparência e acesso à informação pública no Brasil. Na segunda, realizou-se um levantamento de informações por meio do portal do e-SIC, nos itens de relatórios estatísticos e download de dados disponíveis no sítio <http://www. acessoainformacao.gov.br/sistema>, para verificar as demandas por informações financeiras e contábeis e, também, os pedidos registrados no canal de Serviços de Informação ao Cidadão.

Para a análise dos resultados, as informações foram separadas em: categorias gerais e categorias específicas de informações contábeis. As primeiras abrangem todas as demandas por dados registrados no e-SIC, independentemente de seu conteúdo. Essas categorias estão separadas da seguinte forma: Agricultura, extrativismo e pecuária; Comércio, serviço e turismo; Ciência, informação e comunicação; Cultura, lazer e esporte; Defesa e segurança; Educação; Economia e finanças; Governo e política; Habitação; Saneamento e urbanismo; Indústria; Justiça e legislação; Meio ambiente; Pessoa, família e sociedade; Relações internacionais; Saúde; Trabalho; Transporte e trânsito.

Já as informações contábeis governamentais seguem as Normas Brasileiras de Contabilidade Aplicadas ao Setor Público (NBCASP), editadas em 2008 pelo Conselho Federal de Contabilidade, como resultado da reforma da contabilidade governamental. Portanto, as demandas de informações específicas contábeis selecionadas neste artigo abrangem todos os quatro subsistemas de informação da Contabilidade Governamental estabelecidos nas NBCASP, ou seja, informações orçamentárias, patrimoniais, de custos e de compensação.

O universo da pesquisa corresponde a todas as universidades federais brasileiras, no total de $63^{3}$. A amostra trabalhada abrange as 59 instituições cadastradas no sistema e-SIC da Controladoria Geral da União (CGU). Os dados sobre as universidades federais foram coletados no dia 22 de junho de 2014 e cada uma delas foi analisada individualmente. Foram averiguadas as demandas por perguntas registradas. Os resultados também são apresentados separadamente bem como as demandas das dez universidades que mais registraram perguntas no e-SIC. Os dois anos foram explorados tendo como marco temporal o ano de implementação da LAI e separados da seguinte forma: primeiro ano de implementação, de 15 de maio de 2012 a 14 de maio de 2013; e segundo ano, de 15 de maio de 2013 a 14 de maio de 2014.

\footnotetext{
3 Das 63 Universidades Federais cadastradas no Ministério da Educação, 60 também se encontram no e-SIC, sendo que a Universidade Federal do Cariri (UFCA) foi inserida no sistema somente no terceiro ano de implementação da LAl. As outras três universidades (Universidade Federal do Oeste da Bahia (UFOB), Universidade Federal do Sul da Bahia (UFESBA) e Universidade Federal do Sul e Sudeste do Pará (UNIFESSPA)), ainda não se encontram no sistema e-SIC.
} 
A seleção das categorias "Economia e finanças"e "Governo e política" como representantes das informações financeiras e contábeis foi realizada por meio de busca no Vocabulário Controlado do Governo Eletrônico $\left(\right.$ (VCGE) ${ }^{4}$, visando identificar a categoria que enquadraria os termos financeiros e contábeis. Foram utilizadas: (1) Categoria Economia e Finanças - i. Subcategoria Administração Financeira, ii. Subcategoria Encargos Financeiros e iii. Subcategoria Finanças; e (2) Categoria Governo e Política - i. Subcategoria Administração Pública.

Foi analisado, ainda, o perfil dos solicitantes das informações no sistema e-SIC quanto aos seguintes aspectos: pessoa física (PF) e pessoa jurídica (PJ). Foram selecionados para análise, na categoria PF, estudantes e professores, e na PJ, institutos de ensino e pesquisa, sindicatos, órgãos públicos federais e organizações não governamentais.

\section{Resultados e Discussão}

A participação da sociedade no processo de busca pela informação no âmbito das universidades federais pode ser constatada nos resultados apresentados nesta seção. Ressalta-se, inicialmente, o número total de per- guntas registradas no sistema e-SIC, com mais de dez mil perguntas direcionadas a essas instituições, quantidade que se manteve nos dois primeiros anos de implementação da LAl, apresentando variação positiva de quase $6 \%$ no segundo ano. Entre os solicitantes uma pequena parcela, menos de $30 \%$, corresponde a estudantes e professores, sugerindo o interesse da sociedade em geral. Os resultados foram separados por: (i) Categorias gerais; (ii) Perfil dos solicitantes; e (iii) Categorias específicas das informações contábeis. Conforme destacado a seguir, a análise das categorias previamente definidas permitiu conclusões interessantes.

\section{As universidades federais brasileiras e a demanda por informações nas categorias gerais}

Os resultados mostram que, no primeiro ano de implementação da LAI 2012-2013, as perguntas nas categorias gerais direcionadas a apenas dez universidades representam mais de $40 \%$ do total dos pedidos registrados. Já no segundo ano 2013-2014, esse valor caiu para $32 \%$. O número de perguntas registradas por essas universidades é apresentado na Tabela 1.

Tabela 1. Número de perguntas registradas nas categorias gerais por período.

\begin{tabular}{|c|c|c|c|}
\hline \multicolumn{2}{|c|}{ Ano 1 de implementação da Lei de Acesso a Informação (2012-2013) } & \multicolumn{2}{|c|}{ Ano 2 de implementação da Lei de Acesso a Informação (2013-2014) } \\
\hline Instituição & Total (n) & Instituição & Total (n) \\
\hline Universidade Federal de Pernambuco & 621 & Universidade de Brasília & 470 \\
\hline Universidade Tecnológica Federal do Paraná & 611 & Universidade Federal do Rio de Janeiro & 391 \\
\hline Universidade de Brasília & 584 & Universidade Federal de Pernambuco & 363 \\
\hline Universidade Federal do Rio Grande do Sul & 455 & Universidade Federal do Rio Grande do Norte & 346 \\
\hline Universidade Federal de Goiás & 359 & Universidade Federal de Juiz de Fora & 327 \\
\hline Universidade Federal do Rio de Janeiro & 350 & Universidade Federal de Minas Gerais & 312 \\
\hline Universidade Federal Fluminense & 294 & Universidade Federal do Amazonas & 309 \\
\hline Universidade Federal de São Paulo & 274 & Universidade Federal do Espírito Santo & 305 \\
\hline Universidade Federal do Rio Grande do Norte & 270 & Universidade Federal do Paraná & 294 \\
\hline Universidade Federal do Espírito Santo & 268 & Universidade Tecnológica Federal do Paraná & 287 \\
\hline $\begin{array}{l}\text { Total de perguntas registradas no e-SIC das } 10 \text { mais } \\
\text { demandadas }\end{array}$ & 4086 & $\begin{array}{l}\text { Total de perguntas registradas no e-SIC das } 10 \text { mais } \\
\text { demandadas }\end{array}$ & 3404 \\
\hline Total geral de perguntas das universidades federais & 10010 & Total geral de perguntas das universidades federais & 10602 \\
\hline
\end{tabular}

Fonte: Elaborada pelas autoras (2014) com base no Sistema Eletrônico do Serviço de Informações ao Cidadão (e-SIC) da Controladoria Geral da União (CGU).

\footnotetext{
${ }^{4}$ O Vocabulário Controlado do Governo Eletrônico (VCGE) é uma lista de temas do governo que auxilia os usuários a encontrar informações, independente do assunto que o órgão é responsável. O objetivo da árvore é ser intuitiva para a busca de conteúdos de interesse na larga faixa de informações do setor público.
} 
É possível verificar, ainda, que $60 \%$ das universidades federais que detinham o maior número de perguntas registradas no e-SIC no primeiro ano de implementação da LAl permaneceram, no segundo ano, entre as dez mais demandadas. São elas: Universidade de Brasília (UnB), Universidade Federal do Rio de Janeiro (UFRJ), Universidade Federal de Pernambuco (UFPE), Universidade Federal do Rio Grande do Norte (UFRN), Universidade Federal do Espírito Santo (UFES) e Universidade Tecnológica Federal do Paraná (UTFPR).

Já o perfil dos solicitantes das seis instituições que se mantiveram entre as dez mais demandadas, em ambos os períodos analisados, apresenta uma média de 98\% de solicitantes na categoria PF e somente $2 \%$ na PJ. Entre os PF que registraram suas demandas no e-SIC, encontram-se, em média, 20\% de estudantes e $7 \%$ de professores. Já entre os PJ, destacam-se: institutos de ensino e pesquisa, sindicatos, órgãos públicos federais e organizações não governamentais. Ressalta-se que a UnB foi a única universidade federal que apresentou registro de sindicatos entre as pessoas jurídicas. O perfil dos solicitantes, por instituição, é apresentado na Tabela 2.

\section{As universidades federais brasileiras e a demanda por informações contábeis}

Um número considerável de informações contábeis integra as exigências de transparência ativa nos instrumentos desse tipo vigentes no Brasil, dentre eles a LAI. Entretanto, os dados levantados na pesquisa sugerem que essas informações não estão disponíveis nos sites das universidades pesquisadas, isto é, essas instituições parecem não atender, ainda, às exigências de transparência ativa. Essa constatação pode, por outro lado, refletir a dificuldade de localização de informações já disponibilizadas pelo Estado nos portais de transparência, ou mesmo uma necessidade por dados adicionais não abrangidos por esses instrumentos.

Nesse contexto, verificou-se que, no primeiro ano de implementação da LAl, 38 do total das 59 universidades federais pesquisadas apresentaram demandas nas categorias "Informações contábeis", ou seja, 64\% indicaram algum pedido de informações financeiras e contábeis. Já no segundo ano, esse número representava 59\% das instituições pesquisadas. Assim, em média, nos primeiros dois anos de implementação da $\mathrm{LAl}, 61 \%$ das universidades federais estudadas apresentaram alguma demanda por informações financeiras e contábeis, apesar do número relevante de instrumentos de transparência que obriga a transparência ativa no Brasil.

No primeiro ano de implementação da LAl, verificou-se, também, que as dez universidades mais mencionadas no e-SIC representam 75\% da demanda total por informações contábeis de todo o conjunto das 59 instituições. Já na análise do segundo, essa representatividade aumentou para $80 \%$. A mais significativa quanto à demanda contábil foi a Universidade Tecnológica Federal do Paraná (UTFPR), com 200 perguntas registradas, tanto no Ano 1 quanto no Ano 2 de implementação da LAI. O resultado é apresentado na Tabela 3.

Portanto, o número total de demandas por informação contábil de todas as universidades federais

Tabela 2. Perfil de solicitantes registrados no e-SIC por universidade federal.

\begin{tabular}{lcccccccc}
\hline \multicolumn{7}{c}{ Perfil de Solicitantes (\%) } \\
\hline Instituição & PF & PJ & Estudantes & Professores & Sindicato & Inst. Ens. Pesquisa & Orgão Público & ONG. \\
\hline UNB & 99,0 & 1,0 & 18,0 & 5,0 & 25,0 & 0,0 & 25,0 & 25 \\
UFRJ & 98,8 & 1,2 & 26,0 & 7,0 & 0,0 & 20,0 & 20,0 & 20 \\
UFPE & 97,5 & 2,5 & 20,0 & 7,0 & 0,0 & 25,0 & 25,0 & 25 \\
UFRN & 97,5 & 2,5 & 25,0 & 5,0 & 0,0 & 17,0 & 0,0 & 0 \\
UFES & 97,2 & 2,8 & 20,0 & 10,0 & 0,0 & 50,0 & 17,0 & 0 \\
UTFPR & 96,5 & 3,5 & 19,0 & 7,0 & 0,0 & 0,0 & 0,0 & 0 \\
\hline
\end{tabular}

Fonte: Elaborada pelas autoras (2014) com base no Sistema Eletrônico do Serviço de Informações ao Cidadão (e-SIC) da Controladoria Geral da União (CGU).

Nota: Inst. Ens. Pesquisa: Instituição de Ensino e Pesquisa; ONG.: Organização não governamental; PF: Pessoa Física; PJ: Pessoa Jurídica; UFES: Universidade Federal do Espírito Santo; UFPE: Universidade Federal de Pernambuco; UFRJ: Universidade Federal do Rio de Janeiro; UFRN: Universidade Federal do Rio Grande do Norte; UnB: Universidade de Brasília; UTFPR: Universidade Tecnológica Federal do Paraná. 
Tabela 3. Total da demanda por informação contábil nas dez universidades federais mais representativas.

\begin{tabular}{|c|c|c|c|}
\hline \multicolumn{2}{|c|}{ Ano 1 de implementação da Lei de Acesso a Informação (2012-2013) } & \multicolumn{2}{|c|}{ Ano 2 de implementação da Lei de Acesso a Informação (2013-2014) } \\
\hline Instituição & Total $(n)$ & Instituição & Total $(n)$ \\
\hline Universidade Tecnológica Federal do Paraná & 200 & Universidade Tecnológica Federal do Paraná & 200 \\
\hline Universidade Federal de Goiás & 86 & Universidade federal do Acre & 118 \\
\hline Universidade Federal de Pernambuco & 85 & Universidade Federal de Sergipe & 115 \\
\hline Universidade de Brasília & 66 & Universidade Federal de Ouro Preto & 61 \\
\hline Universidade Federal de Sergipe & 62 & Universidade Federal de São Paulo & 55 \\
\hline Universidade Federal do Vale do São Francisco & 62 & Universidade Federal de Goiás & 51 \\
\hline Universidade Federal do ABC & 45 & Universidade Federal do Vale do São Francisco & 46 \\
\hline Universidade Federal de Juiz de Fora & 44 & Universidade Federal de Alfenas & 46 \\
\hline Universidade Federal de Ouro Preto & 40 & Universidade de Brasília & 44 \\
\hline Universidade Federal do Piauí & 36 & Universidade Federal de Pernambuco & 29 \\
\hline $\begin{array}{l}\text { Total de demandas contábeis registradas no } \\
\text { e-SIC das } 10 \text { mais }\end{array}$ & 726 & $\begin{array}{l}\text { Total de demandas contábeis registradas no } \\
\text { e-SIC das } 10 \text { mais }\end{array}$ & 765 \\
\hline $\begin{array}{l}\text { Total de demandas por informação contábil de } \\
\text { todas as universidades federais }\end{array}$ & 964 & $\begin{array}{l}\text { Total de demandas por informação contábil de } \\
\text { todas as universidades federais }\end{array}$ & 946 \\
\hline
\end{tabular}

Fonte: Elaborada pelas autoras (2014) com base no Sistema Eletrônico do Serviço de Informações ao Cidadão (e-SIC) da Controladoria Geral da União (CGU).

manteve-se, praticamente não sofrendo alteração do primeiro para o segundo ano de implementação da LAI. No primeiro ano, o total de solicitações por informações contábeis registradas no e-SIC era de 964 perguntas; no segundo, 946. Ou seja, uma redução de somente $2 \%$. Quanto a esse resultado, deve-se ressaltar que existem variáveis não examinadas no presente artigo, que podem incidir no processo de solicitação e atendimento das demandas. O Artigo 19 (2011), por exemplo, aponta, dentre elas, as limitações dos sistemas de informação governamentais que podem não conseguir ainda otimizar e integrar, de forma adequada, os seus sistemas. Além disso, os solicitantes tendem a emitir pedidos de informação excessivamente amplos temendo que os administradores interpretem as perguntas de forma muito restrita (Artigo 19, 2011).

Existem também variáveis de natureza tecnológica e de recursos humanos que são observadas por pesquisadores do tema (Damatta, 2011; Garrido, 2012; Jardim, 2013). Assim, na política de acesso à informação a falta de tecnologia, de preparação e treinamento dos servidores, de escolas de formação para as práticas básicas de gestão pública, além da falta de uma gestão de informação no setor público, são alguns dos problemas que, apesar da LAl, podem interferir no processo.

Mesmo considerando que essas variáveis são importantes e devem ser examinadas posteriormente, esta pesquisa limitou-se a analisar os dados quantitativos disponibilizados pelo sistema e-SIC com o objetivo de apresentar uma reflexão sobre a aplicabilidade da LAI no Brasil. Deve-se, por outro lado, ressaltar que a própria existência desses dados, acessíveis publicamente para pesquisa acadêmica, é, por si só, um avanço.

\section{Conclusão}

Pode-se, então, afirmar que a transparência dos atos públicos evidenciada particularmente pela possibilidade de acesso às informações públicas, é ferramenta fundamental para maior controle social. No que diz respeito a determinados tipos de informação, como as de natureza contábil, o processo de convergência das normas contábeis aos padrões internacionais no setor público tornou mais evidente essa necessidade por dados mais transparentes e comparáveis.

O acesso à informação referente às contas públicas, dentre elas, a contábil-financeira e orçamentária, permite à sociedade acompanhar os gestores na aplicação dos recursos públicos. Por isso, as informações contábeis possuem destaque em muitos instrumentos de transparência. Não é casual que, entre os dados objeto da transparência ativa, encontrem-se, em grande parte, os contábeis. Nos art. $7^{\circ}$ e $8^{\circ}$ da LAl estão, dentre outras, a 
obrigatoriedade de divulgação de informação pertinente a repasses ou transferências de recursos financeiros, despesas públicas, administração do patrimônio público, utilização de recursos públicos, licitação etc.

Como indicado, constatou-se uma regularidade no número da demanda de informações dirigidas às dez universidades mais solicitadas na amostra de 59 instituições. A proporção de estudantes e professores (respectivamente $21 \%$ e $7 \%$ ) no total de demandantes sugere grande interesse da sociedade em geral, que registrou o maior número de pedidos. Essa constatação reforça o pressuposto defendido por alguns dos autores citados neste artigo, segundo o qual as universidades também estão implicadas nesse processo de transpa-rência e prestação de contas.

A demanda por informações mais específicas, como as de natureza contábil-financeira e orçamentária, no primeiro e segundo ano de vigência da LAI, embora em proporção decrescente (64\% e 59\%, respectivamente) sinaliza para três considerações. A primeira é que do primeiro para o segundo ano a diferença da demanda, em termos proporcionais, foi muito pequena, indicando que as universidades pesquisadas ainda não se ajustaram ao que preconiza a LAI. Outra constatação

\section{Referências}

Artigo 19: Leis de acesso à informação: dilemas da implementação. São Paulo, jul. 2011. Disponível em: <http:// artigo 19.org/doc/Estudos\%20em\%20Liberdade\%20de\% 20Informa\%C3\%A7\%C3\%A30\%201\%20(web).pdf>. Acesso em: 2 jan. 2015.

Bezerra, R.O.; Borges, L.J.; Valmorbida, S.M.L. Análise das prestações de contas na internet da Universidade do Estado de Santa Catarina. Revista GUAL, v.5, n.1, p.66-82, 2012.

Brasil. Lei n 9.755, de 16 de dezembro de 1998. Dispõe sobre a criação de homepage na Internet, pelo Tribunal de Contas da União, para divulgação dos dados e informações que especifica, e dá outras providências. Diário Oficial da União, Brasília, 17 dez. 1998. Disponível em: <http://www.planalto. gov.br/ccivil_03/leis/l9755.htm>. Acesso em: 20 jul. 2014.

Brasil. Lei Complementar $n^{\circ} 101$, de 4 de maio de 2000. Estabelece normas de finanças públicas voltadas para a responsabilidade na gestão fiscal e dá outras providências. Diário Oficial da União, Brasília, 5 maio 2000. Disponível em: <http://www.planalto.gov.br/ccivil_03/leis/lcp/lcp101.htm>. Acesso em: 20 jul. 2014.

Brasil. Decreto n 5.482, de 30 de junho de 2005. Dispõe sobre a divulgação de dados e informações pelos órgãos e entidades é que a existência de instrumentos que obrigam a transparência ativa não é garantia de sua implementação em curto prazo, o que nos leva a sugerir a continuidade da pesquisa em médio e longo prazos. Finalmente, o grande número de demanda dirigida às universidades parece refletir o entusiasmo da sociedade com o início de uma política mais clara de direito à informação no Brasil bem como a necessidade de informações adi-cionais, não disponíveis nos portais de transparência.

A título de reflexão final, talvez uma análise aprofundada sobre o conteúdo das solicitações de informações contábeis pudesse nos esclarecer se se trata das demandas de informações já retratadas no rol mínimo de informações obrigatórias dos instrumentos de transparência ou, ainda, se as solicitações se referem a informações diferentes. Nesse último caso, faz-se importante a verificação desses instrumentos os quais, provavelmente, precisem ser revisados e atualizados conforme as demandas registradas.

\section{Colaboradores}

Todos os autores contribuíram na concepção e desenho do estudo, análise de dados e redação final. da Administração Pública Federal, por meio da Rede Mundial de Computadores: Internet. Diário Oficial da União, Brasília, 1 jul. 2005. Disponível em: <http://www.planalto.gov.br/ccivil_ 03/_Ato2004-2006/2005/Decreto/D5482.htm>. Acesso em: 20 jul. 2014.

Brasil. Portaria Interministerial n 140, de 16 de março de 2006. Disciplina a divulgação de dados e informações pelos órgãos e entidades da Administração Pública Federal, por meio da rede mundial de computadores - internet, e dá outras providências. Diário Oficial da União, Brasília, 17 mar. 2006 Disponível em: <http://www3.transparencia.gov.br/Transparencia Publica/ legislacao/index.html>. Acesso em: 5 jul. 2014.

Brasil. Lei Complementar n 131, de 27 de maio de 2009. Determina a disponibilização, em tempo real, de informações pormenorizadas sobre a execução orçamentária e financeira da União, dos Estados, do Distrito Federal e dos Municípios. Diário Oficial da União, Brasília, 28 maio 2009. Disponível em: <http://www.planalto.gov.br/ccivil_03/leis/lcp/lcp131.htm> Acesso em: 20 jul. 2014.

Brasil. Decreto $n^{\circ}$ 7.185, de 27 de maio de 2010. Dispõe sobre o padrão mínimo de qualidade do sistema integrado de administração financeira e controle, no âmbito de cada ente 
da Federação. Diário Oficial da União, Brasília, 27 maio 2010a. Disponível em: <http://www.planalto.gov.br/ccivil_03/_ato 2007-2010/2010/decreto/d7185.htm>. Acesso em: 20 jul. 2014.

Brasil. Ministério da Fazenda. Portaria no 548, de 22 de novembro de 2010 Estabelece os requisitos mínimos de segurança e contábeis do sistema integrado de administração financeira e controle utilizado no âmbito de cada ente da Federação. Diário Oficial da União, Brasília, 22 nov. 2010b. Disponível em: <http://www.leidatransparencia.cnm.org.br/ img/download/Portaria_MF_n_548_2010.pdf>. Acesso em: 5 jul. 2014.

Brasil. Decreto de 15 de setembro de 2011. Institui o Plano de Ação Nacional sobre Governo Aberto e dá outras providências. Diário Oficial da União, Brasília, 16 nov. 2011 a. Disponível em: <http://www.planalto.gov.br/ccivil_03/_ato2011-2014/2011/ dsn/dsn13117.htm>. Acesso em: 20 jul. 2014.

Brasil. Lei $n^{\circ} 12.527$, de 18 de novembro de 2011. Regula o acesso a informações. Dispõe sobre os procedimentos a serem observados pela União, Estados, Distrito Federal e Municípios, com o fim de garantir o acesso a informações. Diário Oficial da União, Brasília, 18 nov. 2011 b. Disponível em: <http://www. planalto.gov.br/ccivil_03/_ato2011-2014/2011/lei//12527. htm>. Acesso em: 5 jul. 2014.

Brasil. Decreto $n^{\circ} 7.724$, de 16 de maio de 2012. Regulamenta, no âmbito do Poder Executivo Federal, os procedimentos para a garantia do acesso à informação e para a classificação de informações sob restrição de acesso, observados grau e prazo de sigilo conforme Lei n 12.527/2011. Diário Oficial da União, Brasília, 16 maio 2012. Disponível em: <http://www. planalto.gov.br/ccivil_03/_ato2011-2014/2012/decreto/ d7724.htm>. Acesso em: 20 jul. 2014

Brasil. Controladoria Geral da União. Portaria no 277, de 7 de fevereiro de 2013. Institui o Programa Brasil Transparente que tem por objetivo geral apoiar Estados e Municípios na implementação da Lei de Acesso à Informação, Lei no 12.527, de 18 de novembro de 2011, no incremento da transparência pública e na adoção de medidas de governo aberto. Diário Oficial da União, Brasília, 8 fev. 2013a. Disponível em: <http:// www.lex.com.br/legis_24151005_PORTARIA_N_277_DE_7_ DE_FEVEREIRO_DE_2013.aspx>. Acesso em: 20 jul. 2014.

Brasil. Decreto 12 de março de 2013. Altera o Decreto de 15 de setembro de 2011, que institui o Plano de Ação Nacional sobre Governo Aberto. Diário Oficial da União Brasília, 13 mar. 2013b. Disponível em: <http://www.planalto.gov.br/ccivil_03/ _ato2011-2014/2011/dsn/dsn13117.htm>. Acesso em: 20 jul. 2014

Chan, J.L. Government accounting: An assessment of theory, purposes and standards. Public Money and Management, v.23, n.1, p.15-19, 2003. Available from: <http://papers.ssrn.com/ sol3/ papers.cfm?abstract_id=381674>. Cited: Jan. 10, 2012.

Chan, J.L. As NICSPS e a contabilidade governamental de países em desenvolvimento. Revista de Educação e Pesquisa em Contabilidade, v.4, n.1, p.1-17, 2010.

Costa, F.R.; Nery, M.M.R.; Pelissari, A.S. A imagem projetada nos portais corporativos: um estudo multicasos das instituições públicas de ensino superior brasileiras. Revista Espacios, v.34, n.11,2013. Disponível em: <http://www.revistaespacios.com/ a13v34n11/in133411.html>. Acesso em: 30 jan. 2014.

Damatta, R. (Coord.). Sumário executivo: pesquisa diagnóstico sobre valores, conhecimento e cultura de acesso à informação pública no Poder Executivo Federal Brasileiro. Brasília: Controladoria Geral da União, 2011. Disponível em: <http:// www.acessoainformacao.gov.br/central-de-conteudo/ publicacoes/arquivos/pesquisadiagnostico.pdf $>$. Acesso em: 2 maio 2013.

Façanha, L.O. Economia e administração da organização universitária: três modelos de gestão na UFRJ (jul. 1994-jul. 1998). Revista de Administração Pública, v.3, n.33, p.67-98, 1999.

Ferreira, C.D et al. Accountability da gestão pública municipal na região sudeste e a adequação à lei complementar 131/ 2009. In: Congresso USP de Iniciação Científica em Contabilidade, 11., São Paulo, 2014. Anais eletrônicos... São Paulo: USP, 2014. Disponível em: <http://congressousp.fipecafi.org/ web/artigos142014/497.pdf>. Acesso em: 2 jul. 2014.

Gant, J.; Turner-Lee, N. Government transparency: Six strategies for more ppen and participatory government. Washington: The Aspen Institute, 2011.

Garrido, E.P.L. Lei de acesso às informações públicas. Revista Jurídica CNM. Brasília: Confederação Nacional de Municípios, 2012. Disponível em: <http://www.leideacesso.cnm.org.br/ leideacesso/pdf/Artigo_LeideAcessolnformacao.pdf>. Acesso em: 6 out. 2014.

Herbest, F.G. Regime de competência no setor público: a experiência de implementação em diversos países. 2010. Dissertação (Mestrado em Ciências Contábeis), Programa de Pós-Graduação em Ciências Contábeis, Fundação Instituto Capixaba de Pesquisa em Contabilidade, Economia e Finanças, Vitória, 2010.

Jardim, J.M. A implantação da lei de acesso à informação pública e a gestão da informação arquivística governamental. Liinc em Revista, v.9, n.2, p.383-405, 2013. Disponível em: <http:// www.ibict.br/liinc>. Acesso em: 5 out. 2014.

Kanaane, R.; Fiel Filho, A.F.; Ferreira, M. Gestão Pública: planejamento, processos, sistemas de informação e pessoas. São Paulo: Atlas, 2010.

Lyrio, M.V.L. et al. Proposta de um modelo para avaliar o grau de transparência das demonstrações financeiras publicadas por uma instituição pública de ensino superior brasileira: a abordagem da metodologia multicritério de apoio à decisão construtivista: contabilidade, gestão e governança. Revista UnB Contábil, v.11, n.1-2, p.170-186, 2008.

Matias-Pereira, J. Manual de gestão pública contemporânea. 4.ed. São Paulo: Atlas, 2012.

Oliveira, C.M. et al. Transparência e acesso a informação: os desafios enfrentados na implementação da Lei no 12.527 na Fundação Universidade Federal de Rondônia. In: Coloquio de Gestión Universitaria en Américas, 13., 2013, Florianópolis, Anais eletrônicos... Florianópolis: UFSC, 2013. Disponível em <https://repositorio.ufsc.br/handle/123456789/114890>. Acesso em: 14 jun. 2014

Pereira, A.S.; Machado, A.M.; Carneiro, T.C. Avaliação da acessibilidade dos sítios eletrônicos das instituições de ensino su- 
perior brasileiras. Informação \& Sociedade, v.23, n.3, p.123-142, 2013.

Platt Neto, O.A.; Cruz, F.; Vieira, A.L. Transparência das contas públicas: um enfoque no uso da Internet como instrumento de publicidade na UFSC. Revista Contemporânea de Contabilidade, ano 3, v.1, n.5, p.135-146, 2006.

Rodrigues, G. M. Indicadores de transparência ativa em instituições públicas: análise dos portais de universidades públicas federais. Liinc em Revista, v.9, n.2, p.423-438, 2013. Disponível em: <http://www.ibict.br/liinc>. Acesso em: 3 mar. 2014.

Saraiva, L.A.S.; Capelão, L.G.F. A nova administração pública e o foco no cidadão: burocracia X marketing? Revista de Administração Publica, v.32, n.2, p.59-77, 2000.

Sleutjes, M.H.S.; Oliviera, F.B. A crise e a busca de autonomia nas universidades federais brasileiras. Revista de Administração Pública, v.32, n.3, p.29-46, 1998.
Van Der Hoek, M.P. Accountability in the public sector: The dutch experience. Economic Sciences, v.3, n.52, 2010. p.341-352. Disponível em: <http://but.unitbv.ro/BU2010/Series\%20V/ BULETIN\%20V\%20PDF/341\%20Van\%20de\%20Hoek\% 202.pdf>. Acesso em: 21 jul. 2012.

Vicente, E.F.R.; Morais, L.M.; Platt Neto, O.A. A reforma na contabilidade pública brasileira e o processo de convergência: implicações e perspectivas. Revista de Informação Contábil, v.6, n.2, p.1-20, 2012.

Vieira, E.F.; Vieira, M.M.F. Estrutura organizacional e gestão do desempenho nas universidades federais brasileiras. Revista de Administração Pública, v.37, n.4, p.899-920, 2003.

Wynne, A. Is the move to accrual based accounting a real priority for public sector accounting? London: Association of Chartered Certified Accountants, 2004. Available from: <https:/ /bambangkesit.files.wordpress.com/2011/02/accrual-basedaccounting-bab-4.pdf>. Cited: Aug. 21, 2013. 

